\title{
Vaktaalrubriek
}

\section{Aspekte van die hersiening van die Fisikawoordeboek $\mathrm{I}^{*}$}

\author{
D.F. Louw \\ Voorsitter van die Redaksiekomitee
}

In die vorige uitgawe' van hierdie tydskrif is aangedui dat 'n Redaksiekomitee onder die vleuels van die Departement van Nasionale Opvoeding se Nasionale Vakterminologiediens (NVD) benoem is om die tweetalige Fisikawoordeboek $^{2}$ te hersien. Die cerste fase van die projek behels hoofsaaklik die invoeg van aanvullende terme wat sedert 1977 deur medewerkers uit die geledere van die Suid-Afrikaanse Instituut vir Fisika (SAIF) voorgestel is, en daarmee saam die indringende redigering en terminologiese versorging van die woordeboek in sy geheel.

Diegene wat met verwagting na die heruitgawe van die Fisikawoordeboek uitsien - waar die bestaande uitgawe heeltemal uitverkoop is - sal uit die uiteensetting hierna 'n begrip kan kry van die Redaksiekomitee se omvangryke taak. Die Komitee vertrou dat fisici en ander belangstellendes sal verstaan waarom daar om geduld gepleit word terwyl hy na die beste van sy vermoë probeer om 'n deeglike stuk werk te lewer.

\section{KORRIGERING VAN DIE BESTAANDE WOORDE- BOEK}

Die Redaksiekomitee is van mening dat bepaalde regstellings aan en 'n mate van uitdunning van die termskat in die bestaande woordeboek nodig is. Die volgende kategorieë wysigings is hierby ter sprake:-

a) Skryf- en setfoute

Hierdie soort "glippers" wat haas onvermydelik in enige boekwerk voorkom, moet so ver moontlik verwyder word. In die Engels-Afrikaanse afdeling kom daar byvoorbeeld onder die Engelse lemmas skryffoute soos aparature stop, autocorrolation, Bremsstrahlung (breaking radiation), cantiliver en combustion termperature voor. Aan die kant van die Afrikaanse ekwivalente kry ons weer ponsel, snyblock, electroliseer, skroefflyn en oore mikrometer.

In die Afrikaans-Engelse gedeelte word onder die Afrikaanse lemmas onder andere es (met 'n klein letter, as simbool vir einsteinium), ooryp en Zwitterioon (met 'n hoofletter) aangetref. Aan die kant van die Engelse ekwivalente kom weer foutiewe skrifbeelde soos attentuation, tangery, crossm en radiation syndrone voor.

'n Ander soort skryffout kom voor by die vertaling van de Broglie equation, wat in Engels tereg met 'n kleinletter $d$ begin, maar wat in Afrikaans - soos De Villiers - as De Broglie-vergelyking geskryf behoort te gewees het. Dieselfde beginsel behoort ook by die oorsetting van de Haas-van Alphen effect toegepas te gewees het, sodat in Afrikaans De Haas-Van Alphen-effek daarteenoor te staan gekom het. Op soortgelyke wyse is dit korrek om in Engels d'Alembert principle te skryf, maar

*Die redaksie sal kommentaar verwelkom. in Afrikaans moet dit D'Alembert-beginsel wees. Hier kan sommer in dieselfde asem opgemerk word dat die Redaksiekomitee besluit het om die lank gebruiklike koppelteken by die skryf van hierdie soort samestellings met persoonsname te behou. Nóg die los vorm nóg die aanmekaar geskryfde (of is dit deesdae aan mekaar geskryfde?) vorme het die Komitee se seën gekry!

\section{b) Termveelheid}

Na die Komitee se oordeel is daar 'n onnodige veelheid van soortgelyke saamgestelde terme (bv. 'n bepaalde byvoeglike naamwoord, gevolg deur verskillende selfstandige naamwoorde), wat maklik genoeg aan die hand van die gegewe vertalings van die samestellende dele afgelei kan word.

So verskyn daar nie minder nie as 22 Engelse terme met absolute as b.nw., waarvan minstens 7 sonder enige probleem met behulp van die Afrikaanse ekwivalente van terme wat elders in die woordeboek opgeneem is (bv. $a c$ tivity, density, filter en pressure), in Afrikaans oorgesit kan word. Hier kon dus met voordeel uitgedun word.

Daar sal moontlik uiteindelik aangevoer kan word dat die Komitee nog verder kon gesnoei het. By die besluit om ' $n$ bepaalde term (bv. absolute magnitude) te behou, is egter bykomende oorwegings in ag geneem. Waar so 'n Engelse term, waarvan die tweede deel, dus magnitude in die sterrekundige gebruik, 'n ander Afrikaanse ekwivalent moet kry as die gebruiklike grootte of grootheid, word die term tog opgeneem en in Afrikaans met die ekwivalent absolute magnitude weergegee.

Verder word terme waarby die Engelse vorm of die Afrikaanse ekwivalent skryfprobleme kan oplewer (bv. met los of vas skryf of die gebruik van koppeltekens), ten behoewe van die vertaler opgeneem, al kom daar soortgelyke terme in die lys voor. So is air-shower detector (Afr.: lugbuidetektor) naas air shower (Afr.: lugbui) opgeneem, en alkaline-earth metal (Afr.: aardalkalimetaal) naas alkaline earth (Afr.: aardalkaii). Waar die Afrikaanse ekwivalent alfa-emissie (vir alpha-particle emission) met 'n koppelteken geskryf word, word die Engelse trefwoord opgeneem, ondanks die feit dat daar verskeie ander terme met alpha-particle as eerste gedeelte in die lys voorkom. Terloops, sommige van hierdie terme se gevestigde Afrikaanse ekwivalente begin met alfadeeltjie-, en nie met alfa- nie.

\section{c) Ongewenste meervoudsvorme}

Dit is gebruiklik om ' $n$ term in 'n woordeboek in die enkelvoudsvorm op te neem, behalwe waar dit slegs in die meervoudsvorm bekend is (soos bellows en tweezers), of indien die betekenis van die enkelvoudsvorm en die meervoudsvorm verskil, byvoorbeeld content/contents en repair/repairs). Waar Amagat units en compliance constants in die Fisikawoordeboek opgeneem is, 
is die meervoudsvorme egter nie te regverdig nie. Daar kan wel vermeld word dat die Afrikaanse ekwivalent van die Engelse naamwoord resultant inderdaad resultante is, waar die $e$ nie 'n meervoudsvorm aandui nie.

Nog 'n voorbceld van die probleem met meervoudsvorme word by die vertaling van saamgestelde terme met electron teengekom. Electron beam word bv. in die Fisikawoordeboek in Afrikaans met elektronbundel weergegee, maar vir electron cloud word elektronewolk gegee. By albei stelle terme is daar 'n veelheid elektrone ter sprake. Die meervoudsvorm is in die tweede voorbeeld in Afrikaans net so onnodig as wanneer electron sheath met elektronelaag vertaal sou word. Dit is reeds gebruiklik om elektronlaag te skryf, ondanks die feit dat daar beslis meer as een elektron betrokke is.

\section{d) Gewone woorde en niefisikaterme}

'n Woord soos borrow is 'n gewone woord, wanneer dit in die sin van leen gebruik word. Dit geld ook vir discomfort, wat met ongemak vertaal word, en vir disease, wat in Afrikaans as siekte weergegee word. Die Redaksiekomitee het besluit dat hierdie soort terme nie in 'n vakwoordeboek vir fisici tuishoort nie. Hierteenoor word doughnut (met die Amerikaanse vorm donut) cgter behou, omdat dit vir die fisikus 'n vakkundige term is wat soms met toroïed en soms met vloedversterker vertaal moet word.

Daar is in die Fisikawoordeboek ook 'n hele aantal terme soos barium meal, cytology, ganglion en deoxyribonucleic acid wat op ander vakgebiede vir opname in woordeboeke sou kwalifiseer, maar na die Komitee se oordeel regtig nie in 'n fisikawoordeboek tuishoort nie. Hierdie soort terme sal so ver moontlik uit die nuwe woordeboek geweer word.

Die Komitee het hiernaas in gedagte gehou dat daar "grys" gebiede is, dit wil sê vakgebiede waar die fisika en ander natuurwetenskappe soos die chemie, geologie en weerkunde, mekaar oorvleuel - ook wat die terminologie betref. Vakbenamings soos die fisiese chemie, geofisika, mariene fisika en atmosferiese fisika is goed bekend. Om hierdie rede behoort minstens sommige terme uit hierdie vakgebiede in 'n fisikawoordeboek opgeneem te word. Die maatstaf wat hierby aangelê word, is of die term 'n besliste fisikakomponent bevat. 'n Mineraalnaam soos dewindtite gaan dus nie weer opgeneem word nie, maar 'n geofisikaterm soos dip angle sal behou word.

Daar is verder in gedagte gehou dat die fisikus onder andere baie dikwels met 'n groot verskeidenheid wiskunde- en statistiekterme te doen kry. Ondanks die feit dat daar by hierdie terme (soos derivative en diagonal) nie 'n uitgesproke fisikakomponent aan te wys is nie, word hulle tog vir opname in die hersiene uitgawe van die Fisikawoordeboek behou.

(Die leser het moontlik met verbasing hierbo in hierdie afdeling se opskrif die ongewone weglating van die gebuiklike koppelteken by niefisikaterme opgemerk. Aan hierdie aspek word later meer uitvoerig aandag geskenk wanneer die toepassing van sommige nuwe skry freëls wat onlangs deur die Akademie se Taalkommissie geformuleer is, bespreek word.)

\section{e) Meer konsekwente afkortingsbeginsels}

Die volgende lys afkortings (Engels:Afrikaans) laat blyk dat daar in die Fisikawoordeboek nie juis 'n konsekwente afkortingstelsel toegepas is nie:-

$A C$, a.c. (alternating current): WS, ws., wisselstroom (In albei tale word dus 'n keuse tussen hoof- en kleinletters, onderskeidelik sonder en met punte toegelaat; in albei gevalle is die afkortings egter volgens die uitgeskryfde terme in die onderskeie tale.)

a.f. (audio-frequency): of., oudiofrekwensic

(Geen gebruik van hoofletters as alternatiewe vorme erken nie.)

amu, u (atomic mass unit): ame, $u$, atoommassaeenheid (Afkortings van en simbole vir 'n eenheid, met kleinletters, onderskeidelik volgens die uitgeskryfde vorm in die betrokke taal, in albei tale sonder punte.)

$\mathrm{AU}$, au (astronomical unit): AE, ae, astronomiese eenheid (Simbole vir 'n eenheid, waarby hoof- sowel as kleinletters gebruik word, weer eens volgens die uitgeskry fde vorm in die betrokke taal, deurgaans sonder punte.)

bcc (body-centred cubic): bsk, binnesentries kubies (Slegs kleinletters word gebruik. Daar is geen punte nie, ondanks die feit dat daar in albei gevalle los woorde is. Die uitgeskryfde vorm in die onderskeie tale dien as grondslag vir die vorming van die afkorting.)

BThu, Btu (British thermal unit): Bte, Britse termiese eenheid

(Afkorting/simbool vir 'n cenheid, met hoof- sowel as kleinletters, waarby in Engels thermal met $t$ of $T h$ afgekort is. Weer eens is die afkorting/simbool in Afri-

kaans volgens die uitgeskryfde vorm, sonder die gebruik van punte.)

BWR (boiling water reactor): BWR, kookwaterreaktor (Die uitgeskryfde Engelse benaming vir die toestel word ook in Afrikaans gebruik om die afkorting af te lei, deurgaans met hoofletters en sonder punte.)

cal (calorie): cal, kalorie

(Hierdie eenheid word in Afrikaans ook met die Engelse - internasionale? - afkorting/simbool aangedui, met klein letters geskryf, en sonder punte.)

CRT (cathode-ray tube): KSB, katodestraalbuis

('n Afkorting vir die naam van die apparaat, in albei tale volgens die uitgeskry fde vorm, en in albei tale met hoofletters en sonder punte.)

emf (electromotive force): emk, elektromotoriese krag (Hierdie "verskynsel" se afgekorte benaming word in albei tale met kleinletters geskryf - sonder punte, al is daar los woorde. Die uitgeskryfde vorm in die onderskeie tale dien as grondslag vir die vorming van die afkorting.)

kWh (kilowatt hour): kWh, kilowatt-uur

(Ondanks die uitgeskryfde Engelse vorm wat deurgaans met klein letters is, word die afkorting/simbool met 'n hoofletter $\mathbf{W}$ in die middel geskryf, waar die eerste letter van 'n persoonsnaam gebruik word. Dieselfde simbool word ook net so in Afrikaans gebruik, en daar word glad nie punte geplaas nie.)

LMTD (logarithmic mean temperature difference): LGTV, logaritmiesegemiddelde-temperatuurverskil (Die uitgeskryfde vorme in die onderskeie tale is die grondslag vir die afkortings wat met hoofletters en sonder punte geskryf word.)

NMR (nuclear magnetic resonance): KMR, (kernmagnetiese resonansie

(Afkorting van die naam van 'n verskynsel/proses, met 
hoofletters volgens die uitgeskryfde vorm in die betrokke taal, maar in albei tale sonder punte.)

Die Redaksiekomitee het besluit dat daar darem meer orde en reëlmaat op die gebied van afkortings (en simbole) moet kom. Na oorlegpleging - ook met die korresponderende lede - is daar besluit om die stelsel te gebruik waarop in 1984 deur ' $n$ SABS-komitee, verteenwoordigend van sowat 'n dosyn van die grootste gebruikers/skeppers van natuurwetenskaplike en tegnologiese vakterme in Suid-Afrika, ooreengekom is. ('n Verkorte verslag oor die besluite is in 1985 in hierdie tydskrif gepubliseer. $)^{3}$

Die SABS-komitee se aanbevelings/riglyne oor die skryf van afkortings, simbole en akronieme (letterwoorde) kom kortliks op die volgende neer:-

(i) Indien daar' $n$ werklik internasionaal erkende stelsel vir die skryf van simbole (bv. vir chemiese elemente en verbindings, eenhede in die SI-stelsel, ens.) is, word dit in Afrikaans net so geskryf; d.w.s. met hoofletters (veral waar simbole ter sprake is vir eenhede wat van persoonsname afgelei is) en kleinletters na gelang van die term, en sonder punte. So skryf ons dan in Afrikaans:

$\mathrm{g}$ (as simbool vir gram)

mbar (as simbool vir millibar)

$\mathrm{kJ}$ (as simbool vir kilojoule)

$\mathrm{MeV}$ (as simbool vir megaelektronvolt)

Btu (as simbool vir Britse termiese eenheid)

Chu (as simbool vir Celsius-warmte-eenheid)

amu, u (as simbole vir atoommassaeenheid)

$\mathrm{Au}$ (as simbool vir goud)

$\mathrm{NaCl}$ (as simbool vir natriumchloried).

(Volgens die Metriseringsraad ${ }^{4}$ is daar geen erkende internasionale simbool $A U / a u$ vir astronomiese eenheid nie, en word die afkorting $A E$ in Afrikaans daarvoor erken.)

(ii) Wanneer daar nie internasionaal erkende skryfkonvensies ter sprake is nie, word die uitgeskryfde vorm van die vakterm in Afrikaans gebruik om die afkorting te vorm. Gewoonlik word die eerste letter van elke woord in die benaming opgeneem, en die afkorting word uit daardie hoofletters, en sonder punte, saamgestel. Dus:

BHF (vir baie hoë frekwensie)

EMK (vir elektromotoriese krag)

GKTV (vir geslotekring-televisie)

KMR (vir kernmagnetiese resonansie)

KWR (vir kookwaterreaktor)

LSDT (vir lineërespanning-differensiaaltransformator)

VMSKR (vir vloeimetaalverkoelde snelkweekreaktor)

WS (vir wisselstroom)

(iii) In die geval van internasionale letterwoorde (akronieme) soos radar, sonar en laser word die akronieme net so (met kleinletters en sonder punte) geskryf, al sou die uitgeskryfde Engelse vorm vir radar, $\mathrm{nl}$. radio detecting and ranging, ook met radio-opsporing en afstandbepaling (let wel, nie afstandsbepaling nie) vertaal word. (iv) Daar is gevalle waar vakkundiges (veral in bepaalde vak- of geografiese gebiede) van mening is dat 'n afgekorte vorm wat nie volgens die bogemelde riglyne saamgestel is nie, nogtans so gevestig is dat hulle dit in die woordeboek opgeneem wil hê. Dit sal - onder spesiale motivering deur die voorsteller(s) - oorweeg word, en sal gewoonlik as alternatiewe vorm opgeneem word. Die Redaksiekomitee sal dan egter, ter wille van die oortuiging dat 'n konsekwente skryfstelsel voorkeur moet geniet, steeds die voorkeurvorm uitwys, hoewel die toegelate alternatiewe vorm - ooreenkomstig die leksikografiese stelsel - steeds streng alfabeties geplaas sal word.

Die volgende kan as voorbeeld dien:-

BCC (bcc, body-centred cubic) < abbreviation BCC preferred in English > : BSK, bsk, binnesentries kubies, RSK, rsk, ruimsentries kubies <afkortings met hoofletters verkieslik>

Die Redaksiekomitee beoog nie om oor die algemeen die Engelse afkortings te wysig of te standaardiseer nie, maar behou hom die reg voor om wisselvorme wat met die voorkeurvorm in Afrikaans ooreenstem, vir voorkeur uit te sonder. So sal die volgende inskrywings opgeneem word:

$\mathrm{AC}$, a.c. (alternating current) < abbreviation $\mathrm{AC}$ preferred in English >:WS, ws., wisselstroom <afkorting WS in Afrikaans verkieslik>

EMF (emf, electromotive force) (abbreviation EMF preferred in English): EMK, elektromotoriese krag

(v) Daar moet ten opsigte van afkortings nog op een reëling gewys word, en dit is dié ten opsigte van terme wat verboë verlede deelwoorde bevat. Hier word in Afrikaans die eerste letter (as hoofletter) van die stamwoord gebruik, en nie die veelvuldig voorkomende $G$ van ge-nie. Dus skryf ons:

AGR (advanced gas-cooled reactor): VGR, gevorderde gasverkoelde reaktor

en nie $G G R$ as afkorting in Afrikaans nie, want die letter $V$ kom van die stamwoord vorder.

Dieselfde gebruik is reeds gevestig by:

IC (integrated circuit): IB, geïntegreerde baan. (In subparagraaf (ii) hierbo is die eerste letter $G$ van geslote wel in die afkorting GKTV gebruik. Dit is gedoen omdat daar nie 'n ww. sloot/slote bestaan nie.)

Die Redaksiekomitee het met spyt en teleurstelling uit die hersiene uitgawe' van die Afrikaanse woordelys en spelreëls (AWS) daarvan kennis geneem dat die Akademie se Taalkommissie hom oënskynlik glad nie aan die SABS-komitee se aanbevelings oor 'n afkortpraktyk gesteur het nie, ondanks die feit dat ' $n$ volledige voorlegging oor die konsensusriglyne destyds aan die Taalkommissie gestuur is. Dit blyk verder uit die $A W S$ dat die Taalkommissie se voorstelle nie altyd die natuurwetenskaplike gemeenskap tevrede gaan stel nie, omdat hy hom enersyds nie aan die Metriseringsraad se riglyne ten opsigte van die gebruik van bepaalde letters (as simbole) en skryfwyses gesteur het nie. 
Daarmee saam word die algemene vereiste van konsekwentheid ook nie altyd eerbiedig nie. Die $A W S$ gee byvoorbeeld die afkorting $E M K$ naas $e . m . k$. (dus met 'n punt na $e$, ondanks die feit dat $e l e k$ tromotoriese een woord is), en GS naas gs. ; maar dan weer slegs $B H F$ (vir baie hoë frekwensie), en geen ander vorm met kleinletters en punte nie. Verder word $D P M$ naas $d / m$ (vir dele per miljoen) gegee - terwyl $m$ die uitdruklike wetenskaplike simbool vir die eenheid meter is; en dan o.p.m. naas $o / m$ (vir omwentelings per minuut) - terwyl $\mathrm{min}$ tog dic erkende wetenskaplike afkorting vir minuut is.

In 'n volgende aflewering in hierdie reeks sal aandag bestee word aan verdere aspekte waaraan die Redaksiekomitee noodwendig aandag moes skenk - onder andere by die navolg van die Nasionale Vakterminologiediens se voorskrifte ten opsigte van die leksikografiese stelsel wat vir vakwoordeboeke onder die vleuels van die Departement van Nasionale Opvoeding gevolg behoort te word.

\section{LITERATUURVERWYSINGS}

1. Louw, D.F. (1991). Hersiening van die Fisikanvorleboek, S. Afr. Tydskr. Natuuruet. en Tegnol, 10(4), 179.

2. Vaktaalburo van die SA Akademie vir Wetenskap en Kuns (1977). Fisikawoordeboek/Physics Dictionary (Butterworth, Durban)

3. Louw. D.F. \& Vlok. N.V. (1985). 'n Afkortpraktyk vir Afrikaanse vakterme, S. Afr. Tydskr. Natuurwet. en Tegnol., 4, 4-6.

4. Suid-Afrikaanse Buro vir Standaarde (1973). Handleiding tor die gebruik van die SI-stelsel in Suid-Afrika (SABS, Pretoria) p. 13.

5. Taakommissie van die SA Akademie vir Wetenskap en Kuns (1991). Afrikaanse woordelys en spelreèls (Tafelberg). 